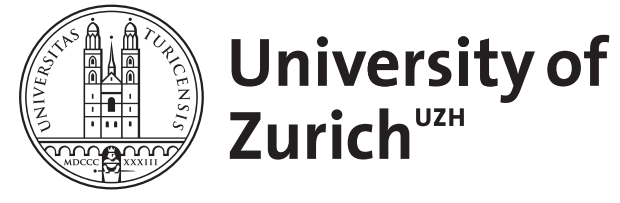

Zurich Open Repository and Archive

University of Zurich

University Library

Strickhofstrasse 39

CH-8057 Zurich

www.zora.uzh.ch

Year: 1999

\title{
Illicit opiates in Toronto: a profile of current users
}

Fischer, B ; Medved, W ; Gliksman, L ; Rehm, J

Posted at the Zurich Open Repository and Archive, University of Zurich

ZORA URL: https://doi.org/10.5167/uzh-94430

Journal Article

Published Version

Originally published at:

Fischer, B; Medved, W; Gliksman, L; Rehm, J (1999). Illicit opiates in Toronto: a profile of current users. European Addiction Research, 7(5):377-415. 
Addiction Research, 1999. Vol. 7, No. 5, pp. 377-415

Reprints available directly from the publisher

Photocopying perminted by license only
(1) 1999 OPA (Overseas Publishers Association) N.V. Published by license under the Harwood Academic Publishers imprint, part of the Gordon and Breach Publishing Group.

\title{
ILLICIT OPIATES IN TORONTO: A PROFILE OF CURRENT USERS
}

\author{
BENEDIKT FISCHER ${ }^{a b^{*}}$, WENDY MEDVED ${ }^{\mathrm{a}}$, LOUIS GLIKSMAN ${ }^{\mathrm{ac}}$ \\ and JÜRGEN REHM ${ }^{\mathrm{ab}}$
}

\author{
${ }^{\mathrm{a}}$ Addiction Research Foundation, Toronto, ${ }^{\mathrm{b}}$ University of Toronto, Toronto and \\ ${ }^{c}$ University of Western Ontario, London
}

\begin{abstract}
Untreated opiate use remains a significant problem in most jurisdictions. As a precursor to developing appropriate treatments and to encouraging these individuals to seek treatment, it is essential that the characteristics of this population be understood. The present study was designed to serve a number of purposes, one of which was to describe the characteristics of a sample of opiate users in Toronto, Canada who were not currently in treatment. One hundred fourteen users using opiates regularly who were not in treatment and who were not actively seeking treatment were recruited through a variety of techniques and then interviewed. The study reports on the demographic characteristics of this sample (age, gender, housing, income and income sources), as well as their drug use patterns, health status, previous treatment history and other lifestyle issues. The results suggest that the sample is relatively healthy, that most of them are users of injectable and prescription opiates as well as other controlled drugs, and that their main sources of income were comprised of social benefits and illegal activities. The implications of these findings for treatment options and harm reduction policies are discussed.
\end{abstract}

Keywords: Opiate use; heroin use; harm reduction; addiction treatment; Canada

The authors would like to acknowledge the cooperation of Dr. Bruna Brands and Ms. Joan Blake, and the Toronto "Finally Understanding Narcotics" (FUN) group in the preparation of this research project. We would also like to thank Laryssa Tyson and Lisa Downs for their skilled assistance in the preparation of this manuscript.

\section{BACKGROUND}

Toronto (Canada) is home to an estimated 10,000 - 15,000 illicit opiate users, primarily heroin addicts (Southtown Consulting 1995, Fischer and Rehm 1997, Remis and Millson 1997). The Toronto opiate and other drug scene, unlike that of many urban European drug scenes, is not openly visible and locally identifiable but rather dispersed and subterranean, and thus

\footnotetext{
* Correspondence Author.
} 
does not qualify as a typical 'open drug scene' (see Bless et al. 1994, Vogt and Weber, in press). The illicit opiate market takes place in a number of different parts of the city, and user populations are typically not concentrated or broadly networked.

Heroin and opiate use in Canada is governed by the Controlled Drugs and Substances Act (CDSA). This recently overhauled law prohibits the possession and supply of heroin. These behaviours are dealt with as criminal offenses with severe criminal punishment, with simple possession of minimal amounts of opiates being punishable by up to 7 years imprisonment (Fischer et al. 1996). In 1995, there were 125 heroin offences in Toronto, which constitutes approximately $3 \%$ of all drug law arrests made in the city. This arrest rate is similar to that of Montreal, Québec, but only one tenth of the heroin arrest rate in Vancouver, BC (Canadian Centre for Justice Statistics 1996). It is currently not possible to systematically profile sentencing outcomes for drug possession offenders, distinguishing for different types of drugs for which the offender had been arrested and charged, because the conviction rates by specific drug categories are not provided.

The number of drug-related deaths per annum, examined by the Toronto coroner's office, in which heroin was identified as one of the contributing factors almost doubled from 35 in 1991 to 65 in 1994, and then fell to 45 in 1995 (latest available data; Metro Toronto Research Group on Drug Use, 1996). Services and treatment options for heroin addicts in Metro Toronto have traditionally been relatively limited. By the end of 1995 , there were around 770 methadone treatment spots in all of the province of Ontario, with approximately 47 local physicians authorized to provide methadone maintenance, two thirds of which were concentrated in the Metropolitan Toronto area (Health Canada 1996, Fischer in press). The majority of the methadone treatment programs in the City were offered through clinical institutions like the Addiction Research Foundation's Opiate Clinic or the Parkdale Clinic, with only a few local physicians prescribing substitution opiates. Most of these programs, however, were rather selective in terms of client recruitment, implemented rigorous client control regimes (mandatory urine testing and counselling, daily pick-ups, etc.) and were based on abstinence-oriented treatment principles. Due to the immense imbalance between demand and supply for methadone treatment in the city, waiting lists until recently have traditionally been at capacity, and many substitution treatment seekers have been kept on lists for years without getting access to methadone treatment. 
Due to some recent changes in the licensing practices of physicians and regulations governing the procedures of methadone maintenance programs in Ontario, the numbers of physicians licensed for methadone prescription as well as maintenance clients in treatment has increased consistently over the past couple of years (Fischer in press). However, it should be noted that relative to international standards, the number of methadone maintenance spots per capita in Canada overall is very low - a situation that has historically been reflected in Ontario and the city of Toronto specifically. In the beginning of 1996, Canada had 107 methadone spots per million inhabitants, compared to 2,000 in Switzerland, 1,000 in Australia, 730 in Belgium and even 441 in the US (Health Canada 1996). Canada's injection drug use population is, on a per capita level, estimated to be the size of Australia's, slightly smaller than that of the US, and about half the size of that of Switzerland (Reuband 1995, Wodak 1992, Nadelmann et al. 1997). The differences in the numbers of methadone treatment spots cannot solely be explained by smaller demand.

In terms of needle exchange facilities, the Toronto situation is best illustrated by the following statistics. There are eight needle exchange facilities in the city. In 1996, a total of 123,500 sterile needles were given out by the city's needle exchange facilities, which on the average translates to slightly over 600 needles per day (Toronto Public Health Department 1997). These numbers are small when compared with those in other jurisdictions: Hamburg (Germany) features an intravenous drug use population (IDU) similar in size to Toronto and exchanges over 3 million needles a year, Oslo's (Norway) IDU population is estimated to be half that size, and over 600,000 needles are exchanged (Fischer 1995, Bretteville-Jensen and Sutton 1996).

\section{HARMS AND CHARACTERISTICS OF OPIATE USE ELSEWHERE}

Illicit opiate use has long been associated with a considerable spectrum of health, social and economic harms and problems (Department of Health and Human Services 1995, Rettig and Yarmolinsky 1995, Swiss Methadone Report 1996). These harm factors related to opiate use may be, for conceptual reasons, divided into two different categories: Actual harm fac- 
tors, meaning harm aspects that are evidenced by opiate users, and risk factors which are created by higher prevalence of exposures or circumstances that make illicit opiate users more prone or likely eventually to incur certain forms of harms. An example of the former category is property crime activity which occurs in conjunction with opiate use. Such crime has negative consequences for the individual user and society, and should be considered a related form of "harm". An example of the latter category would be possible exposure to communicable infectious diseases that eventually may lead to morbidity or mortality. Needle sharing is a risk factor which enhances an opiate user's chances of becoming exposed to infectious diseases like hepatitis or HIV, which may then eventually result in illness and have related individual and social harms and costs.

Harm and risk factors must each be investigated from epidemiological, intervention and treatment, and also prevention perspectives. However, actual harms which are related to opiate use may only be tackled by intervention, which deals with the harms after they have occurred, while risks still leave room for prevention work. To effectively target both aspects of intervention, however, it is rather important to understand what the critical harm and risk indicators and profiles of a given user population are. In general, however, it is important to understand harms and risks associated with illicit opiate use in an interactive, multi-dimensional concept of agency. Harms materializing with illicit opiate use (like high prevalence of crime or unemployment) are rarely directly related to the drug or its user, but rather are an indirect outcome of an interactive process between a host, an agent and an environment, meaning the opiate user, his/her drug of choice and the real life context in which s/he operates (Haddon 1980, Fischer 1995). Many examples in the context of addiction have shown that the simplistic targeting of one of these factors towards change (e.g., through the use of drug laws which are suggested to act as a deterrent to drug users) frequently does not change the overall "harm" situation significantly, and in many cases increases the overall harm and risk situation (Fischer et al. 1997). Rather, attempts to influence the interaction and the interactive outcomes between these three entities may lead to much more significant and efficient ways to reduce the negative aspects associated with illicit opiate use. In fact, this philosophy constitutes one of the basic tenets of the so-called "harm reduction" paradigm (Drucker 1995, Fuchs and Degkwitz 1995, Nadelmann et al. 1997). 
The harm and risk profile characteristics of illicit opiate users generally extend into the following areas of interest (Department of Health and Human Services 1995): Demographic and socio-economic; drug use, demand and supply; physical and psychological health status and risk factors; health and drug treatment variables, and involvement in crime and criminal justice system. Importantly, significant differences have been found in opiate use populations from different jurisdictions or cultural contexts, and opiate use research has also shown substantial shifts in the prevalence and nature of opiate-related harms over time. Solid and elaborate knowledge about the type and prevalence of these aspects is, naturally, necessary for appropriate and effective (proactive or reactive) policy intervention. That is, the high prevalence of property crime or HIV infections associated with illicit opiate users in one jurisdiction should ideally trigger a different policy and program response than in settings where these harms figure relatively substantially lower.

Thus far, hardly any systematic and research based knowledge has been available recently in terms of the harm and risk profiles associated with illicit opiate users from the Metropolitan Toronto area. Subsequently, many policy, program and service options for illicit opiate users have been made on the basis of vague data or secondary estimates (Southtown Consulting 1995).

\section{Empirical trends in opiate-use related harms and risks}

As the available research data on un-treated and illicit opiate users elsewhere indicates, the majority of opiate addicts are under 40 years of age, a finding which is rational since morbidity and mortality do not allow for long opiate use careers (Rettig and Yarmolinsky 1995, Hser 1993). A number of studies have suggested that there has been an increase in the average age of opiate addicts, with various studies now reporting an average population age of 30 years of age (Kemmesies 1996, Buning 1986). These studies have also shown that opiate addiction is predominantly a male phenomenon, with men outweighing women in survey populations by about five to one (Rettig and Yarmolinsky 1995). Numerous opiate users report low levels of social functioning, integration and self-sufficiency. In the user sample entering the Swiss heroin prescription trial, only $47 \%$ of the sample lived in their own housing. Samples of untreated heroin users have consistently shown employment levels limited to between 20 
and 30\% (Maddux and Desmond 1979, Hubbard et al. 1989, Simpson and Sells 1982). In the Swiss sample, only $31 \%$ of the sample had income from employment, while over three quarters received social assistance benefits (Uchtenhagen et al. 1995). A recent study from Oslo, Norway, suggests that within a large sample of injection drug users in Oslo, more than 4 out of 5 users received welfare benefits (Bretteville-Jensen and Sutton 1996). Similar results were found by a study on opiate users in Amsterdam (Grapendaal 1992).

It has been well-documented that due to the circumstances of illicit opiate markets and the need to regularly buy illicit opiate substances at high prices, opiate addicts incur considerable expenses, largely to buy drugs. In the majority of cases, these expenses exceed funds and income available from legitimate sources (Dorn et al. 1994). As a consequence, many opiate addicts resort to illegal (property crime) or semi-legal sources of income generation, most of which involve property crime (monetary or goods that are turned into income), small-scale drug market activities (buying and selling of drugs under net profits) and behaviours like prostitution (in itself not an offense in Canada, but with surrounding behaviours defining it as a "de facto" crime on a street level).

While there are widely differing reports on the level of expenses incurred by opiate addicts, a number of studies have found similar sources of opiate users' income. Two field studies with addicts in Germany suggest that drug addicts spending hundreds of dollars on their drug habits per day is a phenomenon of the past (Kreuzer et al. 1991, Kemmesies 1996). This is partly due to the fact that illicit drug prices in almost all jurisdictions have dropped substantially over the past decade. Both studies suggest that average expenses are in the realm of $\$ 100-\$ 150$ per day and user, although these figures naturally depend on the given market prices for the drugs sought and consumed. Other studies, based upon areas with comparably much higher drug market prices, indicate much higher "cash flow" levels among addict users (Bretteville-Jensen and Sutton 1996, Dorn et al. 1994). These studies have also suggested that welfare benefits, small scale drug market activities (dealing) and property crime constitute the main sources of income for drug addicts, although there are variations between these sources for different socio-cultural environments.

In terms of drug use, illicit opiate users do not tend to limit themselves just to using opiate substances. Opiate user groups report regular or frequent use of cocaine substances by 40 to $70 \%$ of user samples examined 
(Department of Health and Human Services 1995, Hubbard et al. 1989, Ball and Ross 1991, Kemmesies 1996). In Switzerland, for example, 68\% of the heroin addicts who were recruited into heroin maintenance indicated daily use of cocaine (Uchtenhagen et al. 1995). The relatively high prevalence of alcohol, cannabis and amphetamine use among untreated opiate user populations suggests a picture of poly-drug use in which opiates play a prominent but not exclusive role, a fact which is often ignored but which is rather important when thinking about appropriate and effective interventions to reduce the harms associated with substance use (also Skretting et al. 1993, Rettig and Yarmolinsky 1995). In terms of use patterns, opiate addiction is generally characterized by at least daily use of opiates (Simpson and Sells 1982, Hubbard et al. 1989). However, an important change has been reported from European opiate user scenes, where many users have switched from injection as the primary mode of use to "sniffing" or "smoking" (Gossop 1995, Grund 1996, Rehm et al. 1994, Pearson 1987).

One of the main concerns about illicit opiate use, and intravenous drug use in general, is the health status of users, their health risks to themselves, as well as the level of health risk of others who interact with the drug user. In the Swiss opiate user sample, approximately one quarter were diagnosed with a status of "bad physical health", while $42 \%$ were characterized as featuring a status of "bad mental health". Forty-seven percent reported chronic severe health problems, and $75 \%$ of the sample had received two or more sessions of in-patient treatment for health problems in the 6 months prior to the study (Uchtenhagen et al. 1995). However, it has also been found in other jurisdictions that opiate addicts do not use primary or routine medical care more often than non-users despite their substantially higher prevalence of acute health problems. Contact with the health care system is mostly limited to emergency room visits, rendering them a "particularly medically under served population" (Rettig and Yarmolinsky 1995:69). In addition to a "variety of social and medical problems", Rettig and Yarmolinsky conclude on the basis of the ECA sample that heroin addicts showed a comparative "excess of depression and other psychiatric disorders" as well as other "dramatic rates of co-morbidities" (1995:69).

A meta-analysis of opiate user mortality data suggests that the average mortality rate for opiate addicts is around $1 \%$ to $2 \%$ per year (Rehm 1995). A unique longitudinal study which followed a cohort of opiate addicts from 1964 to 1986 (average age at start was $25.4 \mathrm{yrs}$.) found that $28 \%$ of the original sample had died in the years prior to follow-up (Hser et al 
1993). Besides the usual physical health problems, "overdosing" (OD) has emerged as a key morbidity and mortality factor among IDUs. For example, $68 \%$ of the sample in a recent German IDU study reported an OD at least once in their lifetimes, while $23 \%$ had experienced an OD event in the past month (Kemmesies 1996). The dramatic increase in the number of opiate-related overdose deaths in British Columbia through the first half of the 1990s reflected a trend that had been experienced in other jurisdictions (Cain 1994, Fischer 1995).

A key health risk for intravenous drug users is the transmission of infectious diseases via injection or unsafe sexual contacts. A series of studies on IV-opiate users in Zurich reported Hepatitis prevalence rates between 50 and 75 percent (Uchtenhagen et al. 1995). Much of the attention on the infectious disease risks related to IV-drug use has been directed towards the HIV virus. Dramatic differences exist with regard to the actual prevalence and sero-conversion rate among intravenous drug users - ranging from under 5\% to areas with 50-70\% (World Bank 1993, WHO 1993, Fischer et al. 1997). There is clear evidence that regular IV-drug use is one of the strongest predictors of HIV infection at a population level. In some jurisdictions, including the US, IDU populations are responsible for the majority of new HIV infection cases (Nadelmann et al. 1997, DesJarlais 1994, DesJarlais et al. 1994). A comparative sample study of former illicit injection opiate users versus continuing users over a 3-year period showed that the latter are significantly more likely to contract HIV (Metzger et al. 1993, see also Rettig and Yarmolinsky 1995). The enormous public relevance of rates and risk patterns with respect to infectious diseases among IDUs is also underlined by the fact that a considerable number engage in prostitution to generate income (Skretting 1992).

In Canada, the available evidence on HIV rates among intravenous drug users shows a dramatically diversified picture. While recent studies in Toronto have indicated HIV positive rate levels of under 10\%, Montreal's rates seem to lie in the $20 \%$ range, while Vancouver reports a recent explosion in HIV infections with rates in the IDU population reported to be $25 \%$ and higher (Millson 1996, Health Canada 1997). The overall positive impact of needle exchange programs on containing infection prevalence rates as well the reduction of needle sharing events has been well documented (Lurie and Reingold 1993, Nadelmann et al. 1997). However, there are still knowledge gaps with regards to the impact of availability and use of needle exchange facilities on individual IDU's risk patterns over time. 
A series of large-scale studies with opiate addicts entering treatment programs compiled in the US around 1990 suggested that user populations are generally rather heterogeneous in terms of their drug treatment histories. The American National AIDS Demonstration Research (NADR) sample reported that roughly one third of the sample had never been in drug treatment, one third had some non-methadone treatment, and the remaining third had been in methadone treatment before. The Drug Use Forcasting (DUF) study indicated that almost two thirds did not have any drug treatment history at all (Rettig and Yarmolinsky 1995:73ff, Flynn et al. 1994). Similar, less recent overviews as well as a survey of opiate treatment clients in 26 American states, reported that between 36 and $44 \%$ of the samples reported three or more prior treatment attempts (Flynn et al. 1994, Client Data Survey in: Rettig and Yarmolinsky 1995, Simpson et al 1986).

There is no debate over the fact that most illicit, regular opiate use is connected with criminal activity, as established by numerous extensive studies (for good overviews see Johnson et al. 1985, Faupel and Klockars 1987, Hammersley et al. 1989). Crime associated with opiate use falls into two general categories; "drug crime", the violation of drug laws through the possession or dealing activities involving illegal substances, and "drug-related crime", largely property crime to provide money or valuables to allow the addict to buy drugs (Tonry and Wilson 1990, Collins et al 1984, Ball et al 1981). While both types of crime, and the response to them by local criminal justice systems, have substantial implications for the social costs of illicit opiate use and its legal control, drug-related property crime has direct and substantial negative impact on property, safety and general quality of life for the social environments in which illicit drug use occurs.

An important point in terms of harm and social cost associated with illicit drug use, of course, is the source of income for the user. In the Oslo study, $27 \%$ of addicts reported involvement in property crime, while $43 \%$ were involved in drug dealing and $20 \%$ of the overall sample (50\% of females) were involved in prostitution (Bretteville-Jensen and Sutton 1996). However, major differences have been reported across systems. While illegal drug market activities constitute $57 \%$ of drug user income in Oslo and a similar rate of $56 \%$ in a Glasgow study, opiate users in Amsterdam generated only $20 \%$ of their incomes through drug dealing activities. The share of overall income acquired through other property crime activities is about $33 \%$ in Glasgow, and 24\% in Amsterdam respectively (ibid., Hammersley et al 1989, Grapendaal 1992). Generally, the role of illicit 
activities in income generation among illicit opiate users for the Amsterdam sample is considered relatively low for European contexts (Dorn et al. 1994), and numbers are generally estimated to be substantially higher in North American contexts. Grapendaal et al. (1992) have suggested that a negative correlation exists between the extensiveness of welfare systems and the share and relative role of criminal activity for income generation by illicit opiate users in national contexts; that is, the more developed the welfare system, the lower the crime rate.

The majority (between $50 \%$ and $80 \%$ ) of property-related crime in European and Australian states is drug related (Kilias and Uchtenhagen 1996, Grapendaal et al 1995, Kreuzer et al. 1991, Parliamentary Joint Committee 1989). Numerous field studies of addict lifestyles suggest that untreated opiate users, on average, have 12 to 22 criminal activity days per month (Ball et al. 1983, Ball and Ross 1991, Powers and Anglin 1993, Ball and Greberman 1994, Simpson et al. 1995, Department of Health and Human Services 1995). Large-scale analyses of opiate user clients admitted to treatment programs in the US suggest that at least between one third and half of the admissions had engaged in regular criminal activity prior to treatment (Sampson et al. in: Rettig and Yarmolinsky 1995, Flynn et al. 1994). However, other self-report studies suggest that while some opiate users engage either in drug (supply) crime or property crime to support their drug habits, others do not or do so only at minimal levels, and that these differences may be connected to social support and assistance structures available to addicted users (Grapendaal 1992, Bretteville-Jensen and Sutton 1996, Kemmesies 1996).

It has also been suggested that the amount of opiate substances consumed and the frequency and prevalence of drug-related crimes committed by the user are correlated. However, the direction of causality is not clear (Hammersley et al. 1989, Johnson et al. 1985, Faupel 1981, Nurco et al 1985). Due to the high frequency and prevalence of criminal activity among opiate addicts, and in the persistence with regards to these activities, the majority of addicts have had multiple arrest, criminal conviction and incarceration histories, all of which incur massive social costs (Single et al. 1996). In the Swiss heroin user sample, $86 \%$ had been criminally convicted at least once, while over one third had been convicted at least three times. Over half of the sample had served jail time since the onset of opiate use (Uchtenhagen et al. 1995). The large-scale analysis of American opiate addict samples reported an incarceration history for 60 to $80 \%$ of the populations examined (Hubbard et al. 1989, Flynn et al. 1994). 


\section{CONTEXT AND PARAMETERS OF THE STUDY}

Our "harm and social cost of untreated opiate use" study - known under its street name as the "Smack Study"- was conceptualized to serve two main research functions.

First, it is an examination of the scope, parameters and characteristics of illicit opiate use in Metro Toronto. As such, it allows for an account of the harms and social costs associated with untreated opiate use, and thus provides the necessary knowledge base to allow us to design and improve possible interventions, services and harm reduction strategies for this problem area. The study was designed to have an initial baseline measure and then a follow-up measure after one year. This follow-up measure will allow us to examine changes in drug use patterns and related behaviours among an untreated population over time.

Second, the study is an integral element in a much larger treatment evaluation study which assesses the efficacy and cost-effectiveness of a number of methadone programs in Toronto, including a recently revamped, "lower threshold" methadone program at the Addiction Research Foundation in Toronto. This evaluation study will use the data described in this paper as a baseline comparison measure for the ongoing efficacy and cost-effectiveness investigation of some of the methadone maintenance programs in existence in Toronto. It will also help us determine what the fundamental differences are between opiate users who end up in methadone programs versus those who do not. As well, it will help us determine what impacts and harms, associated with illicit opiate use, our methadone programs are capable of altering or reducing in the specific Toronto context.

As its key study areas, this investigation focuses on the following characteristics of this drug-using population: Demographics, socio-economic circumstances, physical and nental health, drug (opiates and other) use prevalence, patterns of use ar.d related harms, sex-related risks, drug use related risks to self and others, health care and treatment system issues, criminal activities and criminal justice system involvement. This paper reports on data gathered and analysed from the first, the baseline, round of interviews with the study sample. 


\section{METHOD}

Ideally, a representative sample of untreated current opiate users in Metro Toronto would be the basis of the current study. However, as opiate users constitute a "hidden population", such a sample is impossible to create, since no population exists from which to draw probability samples (Spreen 1992, Spreen and Zwagstra 1994, Kübler and Hausser 1997). Since only probability samples guarantee representativeness in the statistical sense (Levy and Lemeshow 1991), the current sample cannot be considered to be representative of all untreated opiate users in Toronto. Different alternatives have been developed to overcome this problem, and to approach at least some basic characteristics of representativeness (e.g. Watters and Biernacki 1989, Hartnoll et al. 1995, Kübler and Hausser 1997). We have made use of some of these approaches, specifically, a targeted recruitment campaign and a snowball referral campaign. We hope that the two methods together will help us to attain a sample of typical Metro Toronto opiate users without claiming representativeness in a strict sense.

The subject recruitment period for the study was June 1996 to March 1997. As its main method of recruitment, the study relied on an advertising campaign to enlist subjects. A few thousand handouts about the study were distributed at a number of identified key contact points for opiate and other drug users in Metro Toronto. The flyer outlined the basic scope, procedures and eligibility requirements of the study, ensured confidentiality and anonymity, indicated the renumeration for study subjects (CDN\$25 for the baseline interview), and offered a telephone number to call for further information. The handout was made available at most of the needle exchange facilities, local public health offices and a variety of drop-in centres for opiate and other drug users in Metro Toronto (see below for a discussion of the key implications for sampling). A few ads featuring the same text were run in established city and "scene"-type of weekly or monthly publications.

The second recruitment technique utilized a variant of the "snowball" method, in which subjects who were accepted for the study were asked to contact friends and acquaintances who fit the criteria and were interested in participating in the study.

The study established its own telephone call-in line, where interested potential subjects called and indicated their general interest in participating. After being told what the study was all about, and again securing their 
interest, they were then screened for study eligibility. Two main eligibility criteria for the study were utilized. First, the study only accepted people who were "regular" users of heroin and other opiates, where "regular" use was operationalized as at least daily use over the past week. Second, the study required the subjects to currently not be in treatment, and to not have sought treatment in the three months prior to screening. For ethical reasons, pregnant women were also excluded from the study. The telephone screening also tried to establish the authenticity of the subjects' information regarding their heroin use by asking about previous treatment histories, attempts to quit opiate use, and experiences with withdrawal symptoms. People who were deemed to be eligible for the study were invited to take part in a one-on-one interview.

The interviews were held in a variety of locations across the city, largely in spaces provided by the facilities that had assisted in the study recruitment campaign. The frequency and distribution of reply calls varied substantially, with some weeks being extremely busy ( 25 calls or more) and others being rather slow ( 5 calls or less). Approximately $75 \%$ of the interview appointments were kept. There were a number of attempts by subjects to "double dip," that is, for subjects to try to be interviewed twice in order to collect the fee a second time, which were detected and excluded by the investigators. An average of 4-5 interviews were held per week. The interviews which provided the data presented below were conducted between June 1996 and April 1997.

After meeting the interview subject and again going through a summary of the basic parameters and objectives of the study, the interviewee was given a consent form for the interview. This form would, among other things, outline the confidentiality of the data, and guarantee anonymity. The consent form also expressed the investigator's interest in conducting a follow-up interview in one year with the same data items, and that the same recruitment methods would be used to re-recruit study subjects. That is, flyers would be used to remind subjects to call in for their follow-up interview and the snowball variant whereby interviewees would be asked to tell friends that it was time to be re-interviewed. In order to ensure anonymity as well as data linkage at follow-up, the study used a subject code that consisted of the subject's mother's first name in combination with the day and month of the subject's date of birth.

The data collection itself occurred via a 60-90 minute face-to-face interview, utilizing a mix of some 140 quantitative and qualitative questions. 
The basic categories which the items measured included demographics, social and economic parameters, physical and mental health issues, health and drug treatment systems experiences, indicators of drug use, patterns and harms, sex and drug-use related risks to self and others as well as legal, criminal activities and criminal justice cost issues.

The study trained two interviewers with background in interviewing practices who conducted the pilot testing. The interviews were conducted by one (female) interviewer. Based upon feedback from an opiate user group, revisions were made to the questionnaire while the study was under way. These revisions resulted in some changed or added questions, which resulted in sample size variations for different study items.

\section{STUDY RESULTS}

\section{Demographic and socio-economic data}

By April 1997, a total of 114 subjects had been interviewed in this Toronto study sample. Four out of five subjects $(81.6 \%)$ were male.

In terms of age, the sample did not include any opiate users under the age of 20 . Fifteen percent of the sample were between twenty and thirty years of age. Over half of the sample $(55.3 \%)$ were in their thirties, while about one third $(29.8 \%)$ were older than 40 . This age distribution, with relatively few subjects in the "under 30 " category, seems to confirm the pattern found elsewhere, in which the population of opiate users generally seems to be older than those of other illicit drug using populations.

More than half $(51.8 \%)$ of the sample indicated that they currently live in a rooming house, shelter, hotel, temporarily at someone else's place, or on the street or with no fixed address at all. The other half live in leased accomodation or with family. Almost one out of ten subjects in this sample have children under 18 years of age for whom they are responsible. Almost three quarters of the sample $(72.6 \%)$ reported that they currently live with at least one other person, and of those who live with another person, the majority lived with friends or roommates in a shared accomodation setting, while some lived with their spouse, partner or family. In almost all (86.9\%) of the cases in which the subjects lived with others, people in the environment in which the user was living were aware of their opiate use, and in $63.9 \%$ of the cases the person with whom the respondent was living, was also an opiate user. 
TABLE I Socio-Demographic Characteristics of Total Opiate User Sample, $1996(\mathrm{~N}=114)$

\begin{tabular}{llcc}
\hline & Demographic Characteristic & $(N)$ & $\%$ \\
\hline Sex & & & \\
& Male & 93 & 81.6 \\
& Female & 21 & 18.4 \\
Age & & & \\
& $<20$ & 0 & 0.0 \\
& $21-30$ & 7 & 14.9 \\
& $31-40$ & 63 & 55.3 \\
& $41-50$ & 31 & 27.2 \\
& $51+$ & 3 & 2.6
\end{tabular}

\section{Living Conditions}

Permanent dwelling:

Own / rent / live in parent's home

Temporary dwelling:

Shelter / rooming house / hotel / no fixed address / street

Persons who currently live: $(\mathrm{N}=84)$

$\begin{array}{lcc}\text { Alone } & 23 & 27.4 \\ \text { Spouse or partner } & 13 & 15.5 \\ \text { Parent or sibling } & 10 & 11.9 \\ \text { Friend } & 12 & 14.3 \\ \text { Other residents } & 29 & 34.5 \\ \text { Children } & 4 & 4.8 \\ \text { (Multiple answers possible) } & & \end{array}$

\section{Children}

Persons currently responsible for children under age 18 $(\mathrm{N}=106)$

\section{Employment}

Persons who engaged in paid work in last 12 months

Persons currently doing paid work

$19 \quad 16.7$

1. All percentages refer to the total sample of $\mathrm{N}=114$, unless otherwise indicated in the left column. 
In terms of employment, slightly more than half (53.5\%) of the sample had engaged in some sort of paid work in the 12 months prior to the interview, although more than four fifths $(83.3 \%)$ of the sample were not employed at the time of interview. Of the ones who were employed at the time of the interview $(16.7 \%)$, only a minority $(38.9 \%)$ worked at a steady, full-time job. Of the ones who did engage in any paid work in the past 12 months, more than half $(60.4 \%)$ worked six months or less (overall mean: 23.3 weeks). In addition, more than half of the respondents (55.3\%) indicated that they would have liked to have had more paid work in the last 12 months.

TABLE II Income and Income Sources Over Last 30 Days Among Total Opiate User Sample, $1996(\mathrm{~N}=114)$

\begin{tabular}{|c|c|c|c|c|}
\hline & $(N)$ & $\%$ & $\begin{array}{c}\text { AVG amount } \\
\text { in CDN } \$\end{array}$ & $S D$ in $C D N \$$ \\
\hline \multicolumn{5}{|l|}{ Income } \\
\hline Average total income for last 30 days & 114 & - & $\$ 2,238$ & $\$ 1,764$ \\
\hline \multicolumn{5}{|l|}{ Income Sources } \\
\hline \multicolumn{5}{|c|}{ Money acquired through each income source in last 30 days: } \\
\hline Social Benefits & 86 & 75.4 & 579 & 353 \\
\hline Illegal Activities & 77 & 67.5 & 1.432 & 1,340 \\
\hline Gift / Loan & 56 & 49.1 & 842 & 1,386 \\
\hline Job / Employment & 35 & 30,7 & 1.065 & 1.093 \\
\hline Prostitution & 11 & 9.6 & 2.411 & 2.147 \\
\hline
\end{tabular}

The mean total income for respondents for the 30 days prior to the interview was estimated to be $\$ 2,238$. This included revenue from a variety of sources and was confirmed by a separate question which asked respondents to estimate their monthly living expenses, including drugs.

Respondents listed the following sources that they utilized to generate their incomes: 1 . Social benefits (75.4\%), 2. illegal activities (67.5\%), 3 . gifts and loans from family and friends $(49.1 \%), 4$. employment and work $(30.7 \%)$, and 5 . prostitution $(9.6 \%)$. As the list of average monthly 
incomes from the different sources shows, the incomes from prostitution and illegal activities are the most significant in terms of the amount of revenue they generate. Considering the percentage of the sample that engages in illegal activities for income generation, these are the most significant income sources for the opiate user sample examined. The data also show that most receive welfare benefits, with the average amount received being close to the current maximum welfare benefit amount in Ontario (currently stands at CDN\$520. - per single person/month). The amount of gifts and loans received is almost as high as the average income from employment.

Of those who were asked if there were any sources of income or means to acquire drug money that they would eliminate (e.g., criminal activities or prostitution) if they had sufficient access to their drug of choice, $75.0 \%$ of the overall respondents said yes.

\section{Drug/Opiate use profile}

Almost the total sample of opiate users interviewed (97.4\%) used drugs other than opiates in the $\mathbf{3 0}$ days prior to the interview. Table III indicates that the majority of the sample had been using benzodiazepines as well as cocaine over the past 30 days; a finding that is consistent with other opiate user samples. Crack use is prevalent with about one third of the sample. The use of recreational drugs (alcohol and cannabis) is also prevalent with the majority of the sample.

In terms of heroin use, the mean age of first use of heroin in this sample was in the early twenties, although $17.3 \%$ of the sample indicated that they had used heroin for the first time when they were 16 or younger. On average, this group had used heroin for a period of 10 years. Overall, almost two thirds of the heroin using sample $(61.5 \%)$ had been using heroin for less than ten years, with somewhat over one third having used heroin for 5 years or less. A quarter of the sample $(25.3 \%)$ had been using heroin on a regular basis for a period of 15 years or more.

Almost the entire sample (92.1\%) had used heroin as their opiate drug of choice in the past 30 days. Of the heroin users, $14.3 \%$ had taken it infrequently in the past month, up to a maximum of 2-3 times per week. Seven out often heroin users $(70.5 \%)$ used heroin at least once per day, with the majority of these taking it 2-3 times per day. Only some respondents indicated that they use it either only once a day, or 4 or more times day. 
TABLE III Drug Consumption Patterns of Total Opiate User Sample in Last 30 Days, 1996 $(\mathrm{N}=114)$

\begin{tabular}{ccc}
\hline & $(N)$ & $\%$ \\
\hline Prevalence of Opiate Use & 114 & 100.0 \\
Heroin & 105 & 92.1 \\
Other Opiates & 83 & 72.8 \\
Prevalence of Other Drug Use & 111 & 97.4 \\
Alcohol & 80 & 70.2 \\
Cannabis & 73 & 64.0 \\
Benzodiazepines & 69 & 60.5 \\
Cocaine & 66 & 57.9 \\
Crack & 38 & 33.3 \\
Barbiturates & 15 & 13.2 \\
Methadone & 7 & 6.1 \\
Amphetamines & 5 & 4.4 \\
\hline
\end{tabular}

Two thirds of the sample (66.3\%) indicated that per single use of heroin, they used between $1 / 20$ and $1 / 10$ of a gram. Almost a quarter of the heroin users reported that they usually take a quarter of a gram of heroin or more per single use occasion. In terms of amounts for daily use, the largest number of users used between a quarter and halfa gram. About one third used less than a quarter gram, while the remainder of the sample used more than half a gram some of them, in fact, more than one gram per 24 hour period.

The majority $(86.4 \%)$ of heroin users listed IV injection as their primary mode of use, while $8.7 \%$ listed snorting and $4.9 \%$ smoking. A vast majority of them (79.8\%) used heroin or other opiates regularly in combination with other drugs. Over half of those $(57.1 \%)$ are primarily using heroin or opiates in combination with cocaine or crack.

Three quarters of the total sample had consumed opiates other than heroin in the past 30 days. While opiate use is much less frequent than heroin use, the most prevalent opiate drugs listed were Percodan and Tylenol (T3, T4) with codeine content. Both the average age of first use as well as average length of regular use of other opiates show values similar to those for heroin. The majority of users in the sample use other opiates on a less than daily basis, with only about one quarter of the user sample taking other opiates multiple times per day. 
TABLE IV Prevalence and Frequency of Heroin Use Among Sample Using Heroin, 1996 $(\mathrm{N}=114)$

\begin{tabular}{|c|c|c|}
\hline & $(N)$ & $\%$ \\
\hline Prevalence of heroin use in lifetime & 110 & 96.5 \\
\hline \multicolumn{3}{|l|}{ Length of Use } \\
\hline $\begin{array}{l}\text { Persons who have used heroin on a regular basis in } \\
\text { their lifetime }\end{array}$ & 91 & 82.7 \\
\hline \multicolumn{3}{|l|}{ Number of years of regular use $(N=91)$} \\
\hline$<1$ & 2 & 2.2 \\
\hline $1-5$ & 33 & 36.3 \\
\hline $6-10$ & 25 & 27.5 \\
\hline $11-15$ & 10 & 11.0 \\
\hline $16-20$ & 9 & 9.9 \\
\hline $21+$ & 12 & 13.2 \\
\hline Prevalence of use in last 30 days $(\mathrm{N}=110)$ & 105 & 95.5 \\
\hline \multicolumn{3}{|l|}{ Frequency of use in last 30 days $(N=105)$} \\
\hline Once per week or less & 10 & 9.5 \\
\hline $2-6 \times$ per week & 21 & 20.0 \\
\hline Once per day & 15 & 14.3 \\
\hline $2-3 \times$ per day & 45 & 42.9 \\
\hline $21+\times$ per day & 14 & 13.3 \\
\hline \multicolumn{3}{|l|}{ Average amount per single use in last 30 days $(N=80)$} \\
\hline Half - one tenth & 53 & 66.3 \\
\hline Tenth and a half - two tenths & 9 & 11.3 \\
\hline Quarter gram or more & 18 & 22.5 \\
\hline \multicolumn{3}{|l|}{ Average amount per daily use in last 30 days $(\mathrm{N}=85)$} \\
\hline Less than quarter gram & 30 & 35.3 \\
\hline Quarter - half gram & 39 & 45.9 \\
\hline Over half a gram - one gram & 13 & 15.3 \\
\hline \multirow[t]{2}{*}{ More than one gram } & 3 & 3.5 \\
\hline & AVG (years) & SD (years) \\
\hline Average age at first use $(\mathrm{N}=110)$ & 21.8 & 6.0 \\
\hline Number of years of regular use $(\mathrm{N}=91)$ & 10.0 & 8.5 \\
\hline
\end{tabular}

Over four fifths of the total sample $(83.2 \%)$ considered their drug use, whether opiates or other drugs, to be a problem for themselves. Three quarters $(75.5 \%)$ ofthe sample of opiate users listed heroin as the most 
problematic drug for themselves, while $8.5 \%$ listed other opiates, and $8.5 \%$ suggested that crack or cocaine was most problematic. Almost three quarters of the sample $(74.7 \%)$ said that they used other drugs to minimize or eliminate the withdrawal effects from opiates. Of those, the drugs that were listed as being most used for such purposes were other opiates (53.6\%), benzodiazepines (50.0\%) and alcohol (25.0\%).

When asked about their perceptions about their future drug use, $11.6 \%$ of the sample said that they will likely use more drugs in the future, $17.9 \%$ said that they would continue using approximately the way they do now, $54.5 \%$ said that they would like to continue to use in some reduced form or pattern, and $16.1 \%$ said that they would like to quit totally.

\section{Drug market activities}

Heroin users were asked about the prices that they paid for different amounts of heroin on the street. They reported mean costs of about $\$ 70$ for a quarter gram, $\$ 130$ for a half gram, and $\$ 229$ for one gram. Of those who bought heroin in the past 30 days, the mean number of times they engaged in buying heroin in that period was high (38.8 times), and indicated that they on average bought more than once per day. More than half of the buyers $(55.7 \%)$ indicated that they generally buy between a tenth and a quarter gram per purchase, while $34.2 \%$ indicated that they usually buy half a gram or more per single purchase occasion. The sample of heroin buyers reported that they bought a mean amount of 18.3 grams of heroin in the past 30 days. On average, they reported having spent a mean (gross) amount of $\$ 3,133$ for heroin purchases in the past 30 days (this amount does not take into account their revenue returns for re-selling the heroin).

In terms of other opiate purchases, half the sample (49.5\%) indicated that they had bought opiates other than heroin in the past 30 days, that they did so a mean number of 12.5 times, and spent a mean amount of $\$ 711$ on these substances. The sample reported that they spent a mean amount of $\$ 477$ on illegal drugs other than opiates in the past 30 days.

Close to half the people (46.5\%) who had engaged in buying heroin in the past 30 days indicated that they also engaged in heroin selling activities in the past month. On average, they sold almost half of the heroin (42.2\%) they had originally purchased. Over three quarters of users (76.9\%) said that they shared or gave away some of the heroin they bought in the past month. 
TABLE V Prevalence and Frequency of Opiate Use Among Sample Using Other Opiates Apart From Heroin, $1996(\mathrm{~N}=114)$

\begin{tabular}{|c|c|c|}
\hline & $(N)$ & $\%$ \\
\hline Prevalence of opiate use in lifetime & 110 & 96.5 \\
\hline \multicolumn{3}{|l|}{ Length of Use } \\
\hline $\begin{array}{l}\text { Persons who have used other opiates on a regular } \\
\text { basis in their lifetime }(\mathrm{N}=110)\end{array}$ & 72 & 65.5 \\
\hline \multicolumn{3}{|l|}{ Number of years of use $(\mathrm{N}=72)$} \\
\hline$<1$ & 5 & 6.9 \\
\hline $1-5$ & 20 & 27.8 \\
\hline $6-10$ & 14 & 19.4 \\
\hline $11-15$ & 8 & 11.1 \\
\hline $16-20$ & 11 & 15.3 \\
\hline $21+$ & 14 & 19.4 \\
\hline Prevalence of use in last 30 days $(\mathrm{N}=110)$ & 83 & 75.5 \\
\hline \multicolumn{3}{|l|}{ Opiates most frequently used in last 30 days $(\mathrm{N}=83$ ) } \\
\hline Oxycodone & 41 & 49.4 \\
\hline Codeine & 30 & 36.1 \\
\hline Morphine & 22 & 26.5 \\
\hline Dilaudid & 17 & 20.5 \\
\hline \multicolumn{3}{|l|}{ Frequency of use in last 30 days $(N=83)$} \\
\hline Once per week or less & 25 & 30.1 \\
\hline $2-6 \times$ per week & 23 & 27.7 \\
\hline Once per day & 12 & 14.5 \\
\hline $2-3 \times$ per day & 14 & 16.9 \\
\hline \multirow[t]{2}{*}{$4+\times$ per day } & 9 & 10.8 \\
\hline & AVG (years) & SD (years) \\
\hline Average age at first use $(N=110)$ & 20.8 & 6.4 \\
\hline Number of years of regular use $(N=76)$ & 12.2 & 9.8 \\
\hline
\end{tabular}

Physicians were reported to be another important source of opiate drugs, with $39.5 \%$ of the opiate user sample having seen a doctor in the past 30 days to get a prescription for opiate substances. Those who reported having seen a doctor to get an opiate prescription, visited 2.2 different doctors, had done so on average 3.3 times in the last month, and received a 
mean number of 3.3 prescriptions. Almost half (48.0\%) of those who had received any opiate prescriptions sold part of the opiates that they had received, and $59.1 \%$ gave away or shared some of them.

When asked about their usual means of testing the quality and strength of the heroin that they buy on the street, $52.4 \%$ of heroin users suggest that they use sensory perception means, $33.0 \%$ use a small amount of the opiate substance they bought before they purchase the full amount, and $38.8 \%$ state that they trust their dealer in terms of substance quality.

TABLE VI Purchasing Habits of Opiate User Sample Who Bought Heroin in Last 30 Days, $1996(\mathrm{~N}=114)$

\begin{tabular}{|c|c|c|}
\hline Drug Market Activities & $A V G$ & $S D$ \\
\hline Average price paid for quarter gram of heroin $-\mathrm{CDN} \$(\mathrm{~N}=92)$ & $\$ 70$ & $\$ 58$ \\
\hline $\begin{array}{l}\text { Average number of times users bought heroin in last } 30 \text { days } \\
(N=101)\end{array}$ & 38.8 & 48.5 \\
\hline \multicolumn{3}{|l|}{$\begin{array}{l}\text { Average amount of heroin users bought per purchase in last } 30 \text { days: } \\
(N=79)\end{array}$} \\
\hline Half a tenth - two tenths & 25 & 31.6 \\
\hline Quarter - half a gram & 36 & 45.6 \\
\hline More than half a gram & 18 & 22.8 \\
\hline $\begin{array}{l}\text { Average number of grams heroin users bought in total over the last } \\
30 \text { days }(N=94)\end{array}$ & 18.3 & 30.3 \\
\hline \multirow{2}{*}{$\begin{array}{l}\text { Average amount of money spent on heroin in last } 30 \text { days - CDN } \$ \\
(N=94)\end{array}$} & $\$ 3,133$ & $\$ 3,862$ \\
\hline & $(\mathbf{N})$ & $\%$ \\
\hline $\begin{array}{l}\text { Persons who sold a portion of heroin they bought in last } 30 \text { days } \\
(N=101)\end{array}$ & 47 & 46.5 \\
\hline $\begin{array}{l}\text { Persons who shared or gave away a portion of heroin they bought in } \\
\text { last } 30 \text { days }(\mathrm{N}=65)\end{array}$ & 50 & 76.9 \\
\hline
\end{tabular}

\section{Health and health risks}

The study also investigated indicators of general and drug-specific health problems and health risks experienced by this sample. More than half $(54.4 \%)$ of the study sample reported that they are currently experiencing 
some severe health problems, with one third of the total sample having been hospitalized in the past 12 months. Those who were hospitalized spent an average of 17.8 days in hospital. Almost two thirds of the study sample used emergency services for medical problems at least once in the past 12 months. Of those who received emergency medical services, the mean number of occasions on which such services were utilized was 4.2 times.

TABLE VII Physical Health Status of Total Opiate User Sample, $1996(\mathrm{~N}=114)$

\begin{tabular}{|c|c|c|c|c|}
\hline & & & $(N)$ & $\%$ \\
\hline \multicolumn{5}{|c|}{ Physical Health Problems } \\
\hline \multicolumn{3}{|c|}{ Persons who currently have health problems } & 62 & 54.4 \\
\hline \multicolumn{3}{|c|}{$\begin{array}{l}\text { Persons who experienced a situation in the last } 12 \text { months where they } \\
\text { thought they should seek medical help but decided not to }(\mathrm{N}=95)\end{array}$} & 39 & 41.1 \\
\hline \multicolumn{5}{|c|}{ Hospitalization } \\
\hline \multicolumn{3}{|c|}{ Persons hospitalized in last 12 months } & 38 & 33.3 \\
\hline \multicolumn{3}{|c|}{ Average number of days hospitalized in last 12 months $(\mathrm{N}=38)$} & - & - \\
\hline & AVG & 17.8 & & \\
\hline & SD & 29.0 & & \\
\hline \multicolumn{5}{|c|}{ Emergency Services } \\
\hline \multicolumn{3}{|c|}{ Persons who used emergency services in last 12 months } & 71 & 62.3 \\
\hline \multicolumn{3}{|c|}{$\begin{array}{l}\text { Average number of times persons went to emergency in last } 12 \text { months } \\
(\mathrm{N}=71)\end{array}$} & - & - \\
\hline & AVG & 4.2 & & \\
\hline & SD & 8.1 & & \\
\hline \multicolumn{5}{|c|}{ Physician Visits } \\
\hline \multicolumn{3}{|c|}{ Persons who saw physician in his/her office or clinic in last 12 months } & 90 & 78.9 \\
\hline \multicolumn{3}{|c|}{$\begin{array}{l}\text { Average number of times persons saw physician in his/her office or } \\
\text { clinic in last } 12 \text { months }(\mathrm{N}=90)\end{array}$} & - & - \\
\hline & AVG & 23.7 & & \\
\hline & SD & 56.5 & & \\
\hline \multicolumn{5}{|c|}{ Overdose Experiences } \\
\hline \multicolumn{5}{|c|}{ Persons who overdosed on opiates: } \\
\hline \multirow[t]{2}{*}{$(N=98)$} & Lifetir & & 49 & 50.0 \\
\hline & last $\mathrm{m}$ & & 4 & 4.1 \\
\hline \multicolumn{3}{|c|}{$\begin{array}{l}\text { Persons who have never received medical treatment for any of their } \\
\text { opiate overdoses }(N=48)\end{array}$} & 16 & 33.3 \\
\hline
\end{tabular}


Three quarters of the sample indicated that they have a regular physician or health care provider that they see for medical problems, and slightly over half $(53.9 \%)$ indicated that their doctor was aware of their drug use habit. About 4 out of $5(78.9 \%)$ people indicated that they had seen a physician at least once for a medical problem in the past 12 months. Of those, the mean number of visits was 23.7 for that time period. In spite of this frequent use of physicians, $41.1 \%$ indicated that there had been at least one situation in the past year in which they should have sought medical help and did not.

Half the sample had experienced at least one opiate overdose (OD) incident in their lifetime, and almost one out of ten had overdosed in the past month. Of those who had overdosed at some point in their lives, the mean number of OD incidents experienced was 5.3. One third of the opiate users who had ever overdosed reported that they had never received any medical treatment for these incidents. This sub-sample also indicated that they had received medical help for a mean number of $3.0 \mathrm{OD}$ incidents in their lifetime.

TABLE VIII Mental Health Status of Total Opiate User Sample, $1996(\mathrm{~N}=114)$

\begin{tabular}{lcccc}
\hline \multirow{2}{*}{ Mental Health Indications } & \multicolumn{2}{c}{ Last 30 Days } & \multicolumn{2}{c}{ Lifetime } \\
\cline { 2 - 6 } & $(N)$ & $\%$ & $(N)$ & $\%$ \\
\hline Serious depression & 65 & 57.0 & 93 & 81.6 \\
Sericus anxiety or tension & 84 & 73.7 & 97 & 85.1 \\
Hallucinations & 14 & 12.3 & 46 & 40.4 \\
Difficulty understanding, concentrating or remem- & 63 & 55.3 & 81 & 71.1 \\
bering & & & & \\
Trouble controlling violent behaviour & 20 & 17.5 & 54 & 47.4 \\
Serious thoughts of suicide & 18 & 15.8 & 65 & 57.0 \\
Atternpted suicide & 3 & 2.6 & 36 & 31.6 \\
Used dugs of choise to try to commit suicide & 3 & 3.2 & 23 & 24.5 \\
(N =93, 94) & & & & \\
Prescribed medication for a mental health problem & 16 & 14.0 & 45 & 39.5 \\
\hline
\end{tabular}


Over one third $(36.4 \%)$ of the sample indicated that they currently have concerns about their mental health, and $11.4 \%$ of the sample indicated that they had seen a physician for mental health problems in the past 12 months. $14.0 \%$ of the sample had been prescribed medication for a mental health problem in the past 30 days. For those who did see a physician for mental health problems, the mean number of visits was 18 for that period.

From a list of standard mental health concern issues, half $(50.9 \%)$ of the respondents indicated that they had experienced three or more such indicators during the last 30 days. Anxiety and tension, symptoms of depression as well as memory or concentration difficulties are prevalent with the majority of opiate users in the past month. Over 18 subjects indicated that they had had thoughts of suicide in the past 30 days, while 3 people had actually tried to commit suicide in that period. All these mental health indicators show greatly increased rates when looking at lifetime prevalence. For example, almost one third of the sample had attempted to commit suicide at some point in their lives, and $54.4 \%$ of the sample indicated that they see their mental health concerns as being related to their drug use.

Almost the entire sample, with just a few single exceptions, had used a needle at some point in their lives to inject a drug. Of those who have injected, more than nine of ten people (93.0\%) had done so in the past year. Over seven out often opiate users $(70.2 \%)$ from this sample currently inject drugs using a needle at least once or more times per day.

Of those who use needles to inject drugs, most indicated that they either "almost always" (41.0\%) or "always" (52.0\%) use a new needle when they inject, and $56.9 \%$ indicated that they "always" use a clean spoon. Two thirds of current injectors $(66.7 \%)$ said that they have ever shared a needle with someone, and $33.3 \%$ indicate that they had done so in the past year. Half of those who had been sharing a needle in the past year reported that it had happened more than half a dozen times in that period. An even larger number reported that they had shared other works with someone in the past year. Of those who shared a needle in the past 12 months, exactly half said that they had done so less than half a dozen times in that period. However, $28.1 \%$ of those said that it happened once a month or more frequently. 
TABLE IX Needle Use Habits of Opiate User Sample Who Inject Drugs, $1996(\mathrm{~N}=114)$

(N)

$\%$

\section{Injection Drug Use History}

Persons who have injected any drug:

$\begin{array}{lcc}\text { lifetime } & 111 & 97.4 \\ \text { last year } & 106 & 93.0 \\ \text { last month } & 96 & 84.2 \\ \text { on average injected a drug one or more times per } & 80 & 75.5 \\ 12 \text { months }(\mathrm{N}=106) & & \end{array}$

\section{Location of Injection}

Persons who injected a drug within the last 30 days in the following locations: $(\mathrm{N}=106)$

$\begin{array}{lll}\text { Own home } & 77 & 72.6 \\ \text { Someone else's home } & 70 & 66.0 \\ \text { Public bathroom } & 49 & 46.2 \\ \text { Car } & 37 & 34.9 \\ \text { Street or alley } & 26 & 24.5 \\ \text { Stairwell or hallway } & 22 & 20.8 \\ \text { Abandoned building } & 11 & 10.4 \\ \text { Park or playground } & 10 & 9.4 \\ \text { Crack or speed House / shooting gallery } & 6 & 5.7\end{array}$

\section{Needle Sharing Practices}

Persons who report that they "always" use a new sterile needle when they inject $(N=100)$

Persons who have shared a needle:

$\begin{array}{llll}(\mathrm{N}=105) & \text { lifetime } & 70 & 66.7 \\ & \text { last year } & 35 & 33.3\end{array}$

Persons who have shared other works:

$\begin{array}{llll}(\mathrm{N}=73) & \text { lifetime } & 55 & 75.3\end{array}$

$\begin{array}{lll}\text { last year } & 30 & 41.1\end{array}$ 
Nearly all (93.3\%) of those who inject drugs reported that they had acquired sterile needles in the past month, and more than four out of five $(82.7 \%)$ had acquired 30 needles or more in that period. The mean number of needles acquired by the sample in the past month was 147.2 needles. Almost three quarters $(74.5 \%)$ reported that at the time of the interview they held at least one sterile needle, and of these, the majority (59.0\%) said that they had ten or more clean needles. More than four out of ten people $(44.8 \%)$ said that they currently had the "ideal" number of needles.

In terms of injection habits, over half the sample $(52.4 \%)$ indicated that they injected drugs either "always" alone or "more often alone than with someone". Considerably less (22.9\%) said that they used their drugs more often together with someone than alone, and a similar percentage $(21.9 \%)$ used them "always" with someone else. For nine out often injectors, the ideal place to inject was their own home or somebody else's home. Almost three quarters $(72.6 \%)$ of the injector sample had actually injected in their own home in the month prior to the interview, while two thirds $(66.0 \%)$ had also injected in someone else's home. Considerable parts of this sample indicated that they had injected in a public bathroom, in a car, or in a hallway or stairway over the course of the month prior to the interview.

More than half (55.8\%) of the sample reported that they had had unsafe sex in the year prior to the interview " Unsafe sex" in the study was defined as "having vaginal or anal intercourse without using a latex condom or dental dam, or performing oral sex on a man to ejaculation without using a condom"). Of those who had unsafe sex, almost one third (31.7\%) indicated that they had had unsafe sex with two or more different partners in the past year, and more than half (55.6\%) of these people also suggested that they had done so at least once a week or more frequently. Most $(81.3 \%)$ of the sample actually believe that their opiate use had a direct effect on their sexual practices. The majority of these effects were negative, with over half of the respondents suggesting that the opiate use resulted in a lack of interest in sexual activities.

Of those asked the question, more than nine out of ten (92.6\%) reported that they had been tested for at least one type of existing Hepatitis stream, and $27.5 \%$ of those tested proved to be positive for HepB, while $55.7 \%$ proved to be HepC positive. More than four fifths (89.9\%) of the sample examined had been tested for HIV at some point. Two-thirds $(67.7 \%)$ had been tested in the 12 months prior to the interview, and $6.7 \%$ had tested positive. 
TABLE X Sex and Sex-Related Risks Among Total Opiate User Sample, 1996 (N = 114)

\begin{tabular}{|c|c|c|c|}
\hline & & $(N)$ & $\%$ \\
\hline \multicolumn{4}{|l|}{ Unsafe Sex Practices } \\
\hline \multicolumn{2}{|c|}{$\begin{array}{l}\text { Persons who have had unsafe sex in the last } \\
12 \text { months }(\mathrm{N}=113)\end{array}$} & 63 & 55.8 \\
\hline \multicolumn{2}{|c|}{$\begin{array}{l}\text { Persons who have had unsafe sex in the last } \\
12 \text { months with } 2 \text { or more different partners }(N=63)\end{array}$} & 20 & 31.7 \\
\hline \multicolumn{2}{|c|}{$\begin{array}{l}\text { Persons who have had unsafe sex in the last } 12 \\
\text { months more than one time per week }(N=63)\end{array}$} & 35 & 55.6 \\
\hline \multicolumn{4}{|l|}{ Sex-Related Risks } \\
\hline \multicolumn{4}{|l|}{ Hepatitis } \\
\hline \multicolumn{4}{|c|}{ Persons who have ever been tested for: } \\
\hline$(\mathrm{N}=81)$ & Hepatits B or C & 75 & 92.6 \\
\hline \multicolumn{4}{|c|}{ Persons who have ever tested positive for: } \\
\hline$(N=69)$ & Hepatitis B & 19 & 27.5 \\
\hline$(N=70)$ & Hepatitis C & 39 & 55.7 \\
\hline \multicolumn{4}{|l|}{ HIV } \\
\hline \multicolumn{4}{|c|}{ Persons who have been tested for HIV: } \\
\hline \multirow[t]{2}{*}{$(\mathrm{N}=99)$} & lifetime & 89 & 89.9 \\
\hline & last year & 67 & 67.7 \\
\hline \multicolumn{2}{|c|}{ Persons who have ever tested positive for $\operatorname{HIV}(\mathrm{N}=89)$} & 6 & 6.7 \\
\hline
\end{tabular}

About one quarter $(22.9 \%)$ of those who had ever shared a needle reported that at some point they had shared a needle with someone they knew was HIV positive, and a quarter of these had shared a needle with more than one person who was HIV positive. In addition, $10.8 \%$ of the sample indicated that at some point in their lives, they had had sex with someone who was HIV positive or had AIDS, and one third $(33.3 \%)$ of these people reported that they had done so with more than one person.

Almost one third (30.3\%) of the sample reported that, in the year prior to the interview, they had "never" been worried about being exposed to the HIV virus, while $45.9 \%$ said that they had worried "rarely" or "sometimes", and $23.9 \%$ said that this was the case "often" or "always". Three quarters $(73.8 \%)$ stated that they had "always" refused to share needles for the fear of infection risks, and $54.7 \%$ had "always" refused to have unsafe sex for these reasons. However, $75.0 \%$ of the sample had "never" worried about the possibility of giving HIV to someone else. 


\section{Crime and criminal justice issues}

Due to the definition of non-prescribed opiates as illicit drugs in the Canadian context, all of the sample had possessed and used illegal drugs in the past month. In fact, $67.5 \%$ of the sample self-reported that they had been involved directly in illegal drug market or supply activity in the past 30 days (not including the simple possession of an illegal drug). The mean number of illegal activity days, for that period for the people involved in these drug market activities, was 17.8. They indicated that they had engaged in a mean number of 50.9 such incidents in the 30 days prior to the interview. Specifically; $36.0 \%$ had committed shoplifting or minor theft, with a mean number of activity days of 12.4 (mean number of incidents: 25.8 ); $15.8 \%$ of the total sample had engaged in break and enters (B\&Es), theft, and theft from or of cars, on a mean number of 7.4 activity days (mean number of incidents: 16.0); $14.0 \%$ had committed fraud or forgery, on a mean number of 6.4 activity days (mean number of incidents: 8.7); and two individuals in the sample had committed robbery.

Overall, $46.5 \%$ of the sample had been involved in some property-type offense (not including drug or drug market offenses) in the previous 30 days. On average, they had engaged in at least one of these offences for 14.1 of the previous 30 days.

Those opiate users who had participated in drug market supply activities reported an average income of $\$ 1,070$ for the previous 30 days from these activities. Those who participated in property related criminal activities reported an average income of $\$ 1,341$ from such activities for the last 30 days. The average illegal income, for those who had engaged in illegal activity in the 30 days prior to the interview, was $\$ 1,780$.

Almost the entire sample (93.9\%) had been arrested at least once in their lifetime. In fact, $59.8 \%$ of those arrested had been arrested 10 or more times. The mean number of arrests, for those who had ever been arrested, was 38.2. In addition, most ( $9.7 \%$ ) of those who had ever been arrested said that the majority of these arrests were for illegal activities either related to their drug use or for involvement in activities in which they were trying to get drugs or to get money with which to buy drugs.

In the 12 month period prior to the interview, $13.1 \%$ of the sample had been arrested for a drug offense, $38.3 \%$ had been arrested for a property type of offense, and $13.1 \%$ had been involved in or arrested for a capital offense (including assault, weapons, arson, manslaughter or murder offences). 
TABLE XI History of Involvement with Clininal Justice System Among Total Opiate User Sample, $1996(\mathrm{~N}=114)$

$(N)$

Arrest History - Lifetime

Persons arrested in their lifetime

Average number of arrests in lifetime $(\mathrm{N}=107)$

$$
\begin{array}{ll}
\text { AVG } & 38.2 \\
\text { SD } & 103.5
\end{array}
$$

\section{Arrest History - Last 12 Months}

Persons arrested in the last year for: $(\mathrm{N}=107)$

Property offense

Drug offense

Capital offense

Incarceration - Last 12 Months

Persons who spent time in jail or prison in last 12 months

Persons who spent more than 20 days in jail or prison in last 12 months $(\mathrm{N}=48)$

\section{Current Legal Status}

Persons currently under criminal justice system supervision

In terms of incarceration, $42.1 \%$ of the total sample had spent time in prison in the 12 months prior to the interview. In fact, three of ten people in the overall sample $(28.9 \%)$, or over two thirds $(68.8 \%)$ of those who had been incarcerated in the past year, had spent 20 days or more in prison in that time period. The mean number of davs spent in prison in the previous 12 months, of those who had been incarcerated in that period, was 83.6 (35.2 for total sample).

About half (52.6\%) of the total sample reported that they had no current active involvement with the criminal justice system at the time of the interview (not including criminal records). The remaining $47.4 \%$ of the sample was either in jail, on probation or parole or bail, or awaiting charges or a conviction. 


\section{Opiate substitution/treatment}

More than four out of five opiate users $(89.5 \%)$, reported that they had, at some point in their opiate use careers, taken a significant break from opiate use. Of those who had ever stopped, more than half (52.9\%) had done so 5 times or more.

TABLE XII Drug Treatment of Total Opiate User Sample, $1996(\mathrm{~N}=114)$

\begin{tabular}{|c|c|c|}
\hline & $(N)$ & $\%$ \\
\hline \multicolumn{3}{|l|}{ Drug Treatment History } \\
\hline $\begin{array}{l}\text { Persons who have ever been in a treatment program for } \\
\text { drug or alcohol use }\end{array}$ & 67 & 59.3 \\
\hline \multicolumn{3}{|l|}{ Use of Institutional Treatment } \\
\hline $\begin{array}{l}\text { Persons who have ever been in an institutional treatment } \\
\text { program }(N=67)\end{array}$ & 29 & 43.3 \\
\hline $\begin{array}{l}\text { Persons who have ever been is an institutional treatment } \\
\text { program } 2 \text { or more times }(\mathrm{N}=29)\end{array}$ & 12 & 41.4 \\
\hline \multicolumn{3}{|l|}{ Use of Methadone Treatment } \\
\hline $\begin{array}{l}\text { Persons who have ever been in a methadone treatment } \\
\text { program }(N=67)\end{array}$ & 18 & 26.9 \\
\hline $\begin{array}{l}\text { Persons who have ever been in a methadone treatment } \\
\text { program } 2 \text { or more times }(\mathrm{N}=18)\end{array}$ & 4 & 22.2 \\
\hline \multicolumn{3}{|l|}{ Anticipated Future Use of Methadone Services } \\
\hline \multicolumn{3}{|l|}{$\begin{array}{l}\text { If offered a spot on a methadone treatment program } \\
\text { today, persons who would: }(\mathrm{N}=89)\end{array}$} \\
\hline Accept & 43 & 48.3 \\
\hline Decline & 29 & 32.6 \\
\hline Undecided & 17 & 19.1 \\
\hline
\end{tabular}

In terms of treatment, the majority $(59.3 \%)$ of the sample had been in a drug or alcohol treatment program at some point in their lives. Less than half $(43.3 \%)$ of this treatment sub-sample had been in institutional (in-patient) treatment, and $41.1 \%$ of this latter group had been in institutional treatment twice or more times in their lives. One quarter $(26.9 \%)$ of 
the sub-sample with a treatment history had been in a methadone substitution program at some point in their lives, and again about one quarter of these had been in such a program on two or more separate occasions.

Half of the former methadone patients in the study sample reported that they had been in methadone treatment for six months or less, and the majority of these $(60.0 \%)$ also rated the effects of these programs as either "fair" or "poor". More than one third of the sample (34.7\%) reported that they had incidents in their lives where they actively sought professional help for their drug use, but were not able to find it, and close to half (47.4\%) had at times looked for or used peer support for their drug use.

The study sample presents a rather divided and ambiguous attitude towards methadone substitution treatment. When asked what they would do if they were offered a spot in a methadone program today, about half $(48.3 \%)$ of the sample examined unequivocally said that they would accept such a treatment spot. However, about one third $(32.6 \%)$ of respondents clearly rejected this substitution option, while the remaining opiate users were undecided or felt ambivalently about it.

\section{CONCLUSION}

This study presents a comprehensive account of current risks and harms experienced by an untreated sample of opiate users in Metropolitan Toronto. The findings pose some considerable implications for programming and further research around untreated opiate use in Toronto and elsewhere, while many of them confirm data that have come out of recent opiate user studies conducted in other jurisdictions, mostly European.

One fundamental caveat which has major implications, not only for the generalizability of these findings, but also for further research, must be made about the sampling design of this study. The study sample was primarily recruited at needle exchanges and social service agencies catering to the injection drug using population in Toronto. Because of where they were recruited, we assume that this opiate user sample is relatively conscious of heath risks and harms related to injection drug use, and does not exist in a completely isolated and secluded context, although it has, for various reasons, chosen to or not found its ways into the treatment system. 
Thus, the sample is likely not representative of the entire opiate using population in Toronto.

In fact, the estimates of opiate users for Metro Toronto, when subtracting the opiate users who are in methadone maintenance or other treatment, plus the ones who are regularly embraced by the peripheral health and social service providers, suggest that there must be a much more "hidden population" of opiate users out there that has not been studied in any detail yet (Kübler and Hauser 1997, Watters and Biernacki 1989). The characteristics of this remaining "underground scene" may look very different, and should be subject to further study. This "basic health care" environment in which the study sample was found and located may explain one of the key study findings, specifically that the study sample is relatively "healthy". However, this encouraging piece of data from a public health perspective may not be the case for the rest of the population of "untreated" opiate users in Toronto.

One of the key health indicators, the HIV and Hepatitis prevalence rates found in the sample not only indicate that this study has been dealing with a relatively healthy sample, but also that Toronto may have a unique chance of preventing a dramatic HIV epidemic among opiate IDUs if effective measures are taken immediately. Recent data from Montreal and Vancouver indicate that Canadian opiate user scenes are not at all immune to epidemics of these infectious diseases, and suggest that such an epidemic will occur in Toronto as well, if pragmatic and effective public health oriented measures are not put into place or dramatically expanded (Health Canada 1997, Strathdee et al. 1997, Fischer and Rehm 1997).

Related to this, however, are the discrepancies between perceived health risks of the sample and the actual behaviours in which they engage. While the sample reports high levels of concern and awareness around health and infection risk factors, their reported behaviours (e.g., high rates of needle sharing) suggest that these concerns do not readily translate into less risky behaviour. Again, it must be made clear that with the health and infection risk patterns displayed, infection levels have probably stayed at relatively low prevalence levels due to low baseline levels. However, as soon as the number of infected agents in the user sample rises, the risk behaviours shown suggest that infections may likely spread exponentially.

On the other hand, despite their relatively healthy status, the data also underlined the fact that illicit opiate users are confronted with major obstacles in receiving the basic health care that they desperately need. The high 
rates of overdose that are not medically cared for, the number of medical problems or treatment requests that were not addressed by the health care system make it clear that there are major barriers that need to be overcome in order to reduce opiate use-related harms and costs in the future. Such public health measures must also note the fact that opiate users in Toronto, unlike many European and American jurisdictions where heroin snorting and smoking have become increasingly popular, still primarily rely on injection for their opiate use. At the same time, there is also a high prevalence for the use of other drugs, especially cocaine and benzodiazepines, which may form more harmful drug combinations and effects together with opiate substances. Latest trends even indicate an accelerated shift to cocaine injection habits in IDU populations.

The primary source of income for the opiate users sampled in the Toronto study is through illegal activities, partly in the form of income-generating property crime and partly in the form of small-scale drug dealing and drug market activities. This finding has two major implications. First, it seems to confirm Grapendaal's theory which states that the level of illegal income generating activities with drug addicts is inversely related to the degree of extensiveness of the welfare system surrounding the drug user (Grapendaal 1992, Bretteville-Jensen and Sutton 1996). The majority of the opiate users studied in Toronto also rely on welfare benefits for income generation, but the benefits and amounts seem insufficient to cover the expenses required.

Second, however, these results have implications for "harm reduction" policy making targeted at opiate addicts. The data present more confirmatory evidence that the rather artificial and theoretical division between "supply" and "demand" side, or users and sellers, among opiate users does not hold in practice. In fact, the majority of the opiate users in this sample studied are involved in small-scale dealing for income generation as well. While some policy makers, as a "harm reduction" measure, have suggested a removal and shift of "drug possession" ("demand") from the jurisdiction of police and courts to the health care or treatment system through treatment orders, diversion programs etc. (Health Canada 1997), on the basis of our data it must be recognized that under the current circumstances surrounding illicit opiate use in Toronto, small-scale drug market activities constitute a real and functional part of the opiate user's daily life and existence. Thus, if policy makers intend to remove the Toronto opiate addict from the revolving cycle of the criminal justice system, 
income-generating small-scale drug market (and property crime) activities must be acknowledged as a concommitant of opiate addiction. Thus, pragmatically and effectively shifting the opiate addict away from criminal stigma and punishment to social and health services cannot work in practice if criminal punishment continues to focus on the primary ways through which opiate addicts in Toronto acquire their existential living expenses (which include considerable expenses for drugs). As long as opiate addicts in Toronto are forced to acquire their opiate drugs from illicit sources dealing on black market dynamics, illegal sources of income will have to remain the prime vehicle for addicts to acquire the daily funds needed to survive. A solution for the considerable opiate drugs/crime problem in Toronto thus needs to come to grips with the fact that there is a demand for opiate drugs, and if this demand is not dealt with from a public health perspective, consequences for society at large, as well as the opiate users themselves, will be harmful and costly. All other assumptions would be based on unempirical speculation and distance from the opiate user's reality.

For further and more long-term reduction of social harms and risks associated with illicit opiate use, this study provides another important finding with regards to the necessary and appropriate "continuum of care" for these opiate user populations. While methadone substitution has been more widely introduced and made substantially more accessible to the opiate user population in the Toronto context over the past couple of years, and has been hailed by many as the ultimate form of treatment for opiate users, these data clearly show that MMT has its limits as a treatment option for the opiate user population as a whole (see also Uchtenhagen et al. 1995, Nadelmann et al. 1997, Fischer and Rehm 1997). The fact that only half of the users sampled in this study consider MMT as a treatment option for themselves will require further analysis of qualitative data collected on why methadone is seen to be of such limited value as a substitution treatment for this group of drug users. Some of it may have to do with past negative experiences in the MMT realm, others may not like the idea of substitution in general, the procedures and forms of application, or the substance itself and its pharmacological effects. However, these findings also indicate that, if further substantial social and physical harms and related costs are to be prevented, there is a dire need in the Toronto setting to establish and expand a much wider "continuum of care" for illicit opiate use, that for once should also include a much broader, more diverse and 
more user-oriented spectrum of substitution substances and procedures than the ones practised currently. Other jurisdictions have made much headway in this regard over the past few years, and have much positive experience to offer.

\section{References}

Swiss Methadone Report. (1996) Berne/Toronto: Swiss Federal Office of Public Health/Addiction Research Foundation.

Ball, J., \& Greberman, S. (1994). Lifetime Arrest Rates of Heroin Addicts in Baltimore. Problems of Drug Dependence, 2.

Ball, J., Rosen, L., Flueck, J., \& Nurco, D. (1981). The Criminality of Heroin Addicts When Addicted and When Off Opiates. In J. Inciardi (Ed.), The Drugs-Crime Connection (pp. 39-65). Beverly Hills: Sage Publications.

Ball, J., \& Ross, A. (1991). The Effectiveness of Methadone Maintenance Treatment. New York: Springer-Verlag.

Ball, J., Shaffer, J., \& Nurco, D. (1983). The Day-to-Day Criminality of Heroin Addicts in Baltimore - A Study in the Continuity of Offence Rates. Drug and Alcohol Dependence, 12, 119-142.

Bless, R., Korf, D., \& Freeman, M. (1994). Open Drug Scenes: A Cross-National Comparison of Concepts and Urban Strategies. Amsterdam: The Amsterdam Bureau of Social Research and Statistics.

Bretteville-Jensen, A., \& Sutton, M. (1996). The Income -Generating Behaviour of Injecting Drug-Users in Oslo. Addiction, $9 l(1), 63-79$.

Buning, E. (1986). Demethadonverstrekking in ciifers. Amsterdam: Municipal Health Services.

Cain, V. (1994). Report of the Task Force into Illicit Narcotic Overdose Deaths in British Columbia Burnaby: Office of the Chief Coroner, Province of British Columbia.

Canadian Centre for Justice Statistics. (1996). Drug Offense, Arrest and Charge Data under $N C A$. Ottawa: Canadian Centre for Justice Statistics.

Collins, J., Hubbard, R., \& Rachal, J. (1984). Heroin and Cocaine Use and Illegal Income: Research Triangle Institute - Centre for Social Research and Policy Analysis.

Department of Health and Human Services. (1995). Methadone Maintenance Treatment: Translating Research into Policy. Bethesda: Department of Health and Human Services.

DesJarlais, D., Friedman, S., Sotheran, J., Wenston, J., Marmor, M., Yancovitz, S., Frank, B., \& Mildvan, D. (1994). Continuity and Change Within an HIV Epidemic. Injecting Drug Users in New York City, 1984 through 1992. Journal of the American Medical Association. 271,121-127.

DesJarlais, J. (1994). Cross-national Studies of AIDS Among Injecting Drug Users. Addiction. 89, 383-392.

Dorn, N., Baker, O., \& Seddon, T. (1994). Paying for Heroin: Estimating the Financial Cost of Acquisitive Crime Committed by Dependent Heroin Users in England and Wales. London: The Institute for the Study of Drug Dependence.

Drucker, E. (1995). Harm Reduction: a public health strategy. Current Science, 1, 64-70.

Faupel, C. (1981). Drug Treatment and Criminality - Methodological and Theoretical Considerations. In J. Inciardi (Ed.), The Drugs-Crime Connection (pp. 183-205). Beverly Hills: Sage Publications.

Faupel, C., \& Klockars, C. (1987). Drugs-Crime Connections: Elaborations from the Life Histories of Hard-Core Heroin Addicts. Social Problems, 34(1), 54-68.

Fischer, B. (1995). Drug, Communities and "Harm Reduction" in Germany - The New Relevance of "Public Health" Principles in Local Responses. Journal of Public Health Policy, 16(4), 389-411. 
Fischer, B. (in press). Prohibition, Prescriptions and Politics. The Turbulent History of Methadone Maintenance in Canada. Journal of Public Health Policy.

Fischer, B., Erickson, P., \& Smart, R. (1996). The New Canadian Drug Law: One Step Forward, Two Steps Backward. The International Journal of Drug Policy, 7(3), 172-179.

Fischer, B., Kendall, P., Rehm, J., \& Room, R. (1997). Charting WHO-Goals for Licit and Illicit Drugs for the Year 2000: Are We "On Track"? Public Health, 111(5):271-277.

Fischer, B., \& Rehm, J. (1997). The Case for a Heroin Substitution Treatment Trial in Canada. Canadian Journal of Public Health, 88(6):367-370.

Flynn, P., Craddock, S., Gail, M., Luckey, J., \& Hubbard, R. (1994). Client Characteristics Among Admissions to Methadone Treatment Programs in Two National Samples. Research Triangle Park.

Fuchs, W., \& Degwitz, P. (1995). Harm Reduction in Europe - Trend, Movement or Change of Paradigma Eur Addict Research 1,81-85.

Gossop, M. (1995). Chasing the Dragon: Research into Heroin Smoking in Britain. European Addiction Research, $1,42-49$.

Grapendaal, M. (1992). Cutting Their Coat According to Their Cloth: Economic Behavior of Amsterdam Opiate Users. The International Journal of the Addictions, 27(4), 487-501.

Grapendaal, M., Leuw, E., \& Nelen, H. (1992). Drugs and Crime in an Accomodating Social Context: the Situation in Amsterdam. Contemporary Drug Problems, 19, 303-326.

Grapendaal, M., Leuw, E., \& Nelen, H. ( 1995). A World of Opportunities. Life-style and Economic Behavior of Heroin Addicts in Amsterdam. Albany, New York: SUNY Press.

Grund, J. (1996). Drug Use as a Social Ritual: Functionality. Symbolism and Determinants of Self-regulation. Rotterdam: IVO-Addiction Research Institute.

Haddon, W. (1980). Advances in the Epidemiology of Injuries as a Basis for Public Policy: 95 Public Health Reports.

Hammersley, R., Forsyth, A., Morrison, V., \& Davies, J. (1989). The Relationship Between Crime and Opiod Use. British Journal of Addiction, 84, 1029-1043.

Hartnoll, R., Balsa, C., \& Griffiths, P. (1995). Handbook on Snowball Sampling. Strasbourg.

Health Canada. (1996). International Survey on the Use of Methadone in the Treatment of Narcotic Addiction: Summary of Results. Ottawa: Health Canada.

Health Canada. (1997). HIV, Aids and Injection Drug Use - A National Action Plan. Ottawa: Health Canada.

Hser, Y. (1993). Prevalence estimation techniques for drug-using populations. Data sources: problems and issues. Journal of Drug Issues. 23,217-228.

Hser, Y., Anglin, M., \& Powers, K. (1993). A 24 Year Follow-Up of California Narcotics Addicts. Archives of General Psychiatry, 50, 577-584.

Hubbard, R.. Marsden, M., Rachal, J., Harwood, H., Cavanaugh, E., \& Ginzburg, H. (1989). Drug Abuse Treatment: A National Study of Effectiveness. Chapel Hill: University of North Carolina Press.

Johnson, B., Goldstein, P., Preble, E., Schmeidler, J., Lipton, D., \& Miller, T. (1985). Taking Care of Business: The Economics of Crime by Heroin Abusers. Lexington: Lexington Books.

Kemmesies, U. (1996). Offene Drogenszene und Druckräume. Wiener Zeitschrifffür Suchtforschung 19(3/4), 17-32.

Killias, M., \& Uchtenhagen, A. (1996). Does Medical Heroin Prescription Reduce Delinquency Among Drug Addicts? On the Evaluation of the Swiss Heroin Prescription Projects and its Methodology. Studies on Crime and Crime Prevention, S(2), 245-256.

Kreuzer, A., Römer-Klees, R., \& Schneider, H. (1991). Beschaffungskriminalität Drogenabhängiger. BKA-Forschungsreihe.

Kuibler, D., \& Hausser, D. (1997). The Swiss Hidden Population Study: practical and methodological aspects of data collection by privileged access interviewers. Addiction, 92(3), 325-334.

Levy, P., \& Lemeshow, S. (1991). Sampling of Populations: Methods and Applications. New York: Wiley. 
Lurie, P., \& Reingold, A. (1993). The Public Health Impact of Needle Exchange Programs in the United States and Abroad. Berkeley: University of California, Institute for Health Policy Studies,

Maddux, J., \& Desmond, D. (1979). Crime and Treatment of Heroin Users. The International Journal of the Addictions, 14(7), 891-904.

Metro Toronto Research Group on Drug Use. (1996). Drug Use in Metropolitan Toronto. Toronto: Metro Toronto Research Group on Drug Use.

Metzger, D., Woody, G., McLellan, A., Druley, P., DePhillips, D., O'Brien, C., Stolley, P., \& Abrutyn, E. (1993). HIV Seroconversion Among in and out of Treatment Intravenous Drug Users: An 18-month Prospective Follow-up. AIDS. 6(9), 1049-1056.

Millson, M. (1996). WHO Multi-city Study on Drug Injecting \& Risk of HIV Infection. Toronto: NHRDP.

Nadelmann, E., McNeely, J., \& Drucker, E. (1997). International Perspectives. In J. H. Lowinson, P. Ruiz, R. B. Millman, \& J. G. Langrod (Eds.), Substance Abuse: A Comprehensive Textbook. Baltimore, MD.: Williams \& Wilkins.

Nurco, D., Ball, J., Shaffer, J., \& Hanlon, T. (1985). The Criminality of Narcotics Addicts. Journal of Nervous and Mental Disease. 173, 94-102.

Parliamentary Joint Committee on the National Crime Authority. (1989). The Social Costs of Prohibition: Adelaide Parliamentary Joint Committee on the National Crime Authority.

Pearson, G. (1987). The New Heroin Users. Oxford: Blackwell.

Powers, K., \& Anglin, M. (1993). Cumulative versus stabilizing effects of methadone maintenance. Evaluation Review. 17(3), 243-270.

Rehm, J. (1995). Konsumformen und Verbreitung illegaler Drogen in der Schweiz, in: Illegale Drogen in der Schweiz 1990-1993. Zürich: Seismo Verlag.

Rehm, J., Beroud, G., \& Müller, R. (1994). Folienrauchen in der Schweiz: Ergebnisse einer Expertenbefragung. Sozial- und Präventivmedizin, 39, 370-371.

Remis, R., \& Millson, M. (1997). The HIV Epidemic Among Injection Drug Users in Ontario: The Situation in 1997. Toronto: University of Toronto - Department of Preventive Medicine and Biostatistics.

Rettig, R., \& Yarmolinsky, A (1995). Federal Regulationof Methadone Treatment.Washington, D.C.: Committee on Federal Regulation of Methadone Treatment - Institute of Medicine.

Reuband, K. (1995). Drug Use and Drug Policy in Western Europe. European Addiction Research, $1(1-2), 32-41$.

Simpson, D., Joe, G., Lehman, W., \& Sells, S. (1986). Addiction Careers: Etiology, treatment and 12 year follow-up procedures. Journal of Drug Issues, 16, 107-121.

Simpson, D., Joe, G., Rowan-Szal, G., \& Greener, J. (1995). Client engagement and change during drug abuse treatment. Journal of Substance Abuse. 7(1), 117-134.

Simpson, D., \& Sells, S. (1982). Effectiveness of Treatment for Drug Abuse: An Overview of the DARP Research Program. Advances in Alcohol and Substance Abuse. 2(1), 7-29.

Single, E., Robson, L., Xie, X., \& Rehm, J. (1996). The Costs of Substance Abuse in Canada. Ottawa: Canadian Centre on Substance Abuse.

Skretting, A. (1992). Injecting Drug Users in Oslo. Narkotskaforebygging, 82-95.

Skretting, A., Ervik, R., \& Oie, K. (1993). The Needle Exchange Service in Oslo. A User Survey. Oslo: National Institute for Alcohol and Drug Research.

Southtown Consulting. (1995). Heroin Activity in Metro Toronto. Toronto: MTATSC.

Spreen, M. (1992). Rare populations, hidden populations and link-tracing designs: what and why? Bulletin de Methodologie Sociologique, 36, 34-58.

Spreen, M., \& Zwaagstra, R. (1994). Personal Network Sampling, Outdegree Analysis and Multilevel Analysis: Introducing the Network Concept on Studies of Hidden Population. International Sociology, 9.475-491.

Strathdee, S., Patrick, D., Currie, S., Cornelisse, P., Rekart, M., Montaner, J., Schechter, M., \& O'Shaughnessy, M. (1997). Needle exchange is not enough: Lessons from the Vancouver injecting drug use study, AIDS, $1 l$, F59-F65. 
Tonry, M., \& Wilson, J. (1990). Drugs and Crime. Chicago: University of Chicago Press.

Toronto Public Health Department. (1997). Information on Needle Exchange - Personal Communication with Dr. Richard Gould (Assistant Medical Officer of Health) .

Uchtenhagen, A., Gutzwiller, F., \& Dobler-Mikola. A. (1995). Versuche für eine ärztliche Verschreibung von Betäubungsmitteln. Zürich: Institut fur Suchtforschung in Verbindung mit der Universität Zurich.

Vogt, I., \& Weber, U. (in press). Living in the Open Drug Scene in Frankfurt / Main. Addiction Reserach.

Watters, J., \& Biernacki, P. (1989). Targeted Sampling: Options for the Study of Hidden Populations. Social Problems, 36(4), 4l6-430.

Wodak, A. (1992). HIV Infection and Injecting Drug Use in Australia. Journal of Drug Issues. 22(3), 549-562.

World Bank. (1993). World Development Report 1993 - Investing in Health - World Devolopment Indicators. New York: Oxford University Press. 